\title{
Reduced Cardiorespiratory Fitness after Stroke: Biological Consequences and Exercise-Induced Adaptations
}

\author{
Sandra A. Billinger, ${ }^{1}$ Eileen Coughenour, ${ }^{1}$ \\ Marilyn J. MacKay-Lyons, ${ }^{2}$ and Frederick M. Ivey ${ }^{3,4}$ \\ ${ }^{1}$ Department of Physical Therapy and Rehabilitation Science, University of Kansas Medical Center, 3901 Rainbow Blvd, Mail Stop 2002, \\ Kansas City, KS 66160, USA \\ ${ }^{2}$ School of Physiotherapy, Dalhousie University, 5869 University Avenue, Halifax, NS, Canada B3H 3J5 \\ ${ }^{3}$ Department of Neurology, University of Maryland School of Medicine, Baltimore, MD 21201, USA \\ ${ }^{4}$ Division of Gerontology and Geriatric Medicine, Department of Veterans Affairs and Veterans Affairs Medical Center, Geriatric \\ Research, Education and Clinical Center (GRECC), Baltimore, MD 21201, USA
}

Correspondence should be addressed to Sandra A. Billinger, sbillinger@kumc.edu

Received 14 May 2011; Accepted 27 June 2011

Academic Editor: Gert Kwakkel

Copyright ( $) 2012$ Sandra A. Billinger et al. This is an open access article distributed under the Creative Commons Attribution License, which permits unrestricted use, distribution, and reproduction in any medium, provided the original work is properly cited.

\begin{abstract}
Evidence from several studies consistently shows decline in cardiorespiratory (CR) fitness and physical function after disabling stroke. The broader implications of such a decline to general health may be partially understood through negative poststroke physiologic adaptations such as unilateral muscle fiber type shifts, impaired hemodynamic function, and decrements in systemic metabolic status. These physiologic changes also interrelate with reductions in activities of daily living (ADLs), community ambulation, and exercise tolerance, causing a perpetual cycle of worsening disability and deteriorating health. Fortunately, initial evidence suggests that stroke participants retain the capacity to adapt physiologically to an exercise training stimulus. However, despite this evidence, exercise as a therapeutic intervention continues to be clinically underutilized in the general stroke population. Far more research is needed to fully comprehend the consequences of and remedies for CR fitness impairments after stroke. The purpose of this brief review is to describe some of what is currently known about the physiological consequences of CR fitness decline after stroke. Additionally, there is an overview of the evidence supporting exercise interventions for improving CR fitness, and associated aspects of general health in this population.
\end{abstract}

\section{Introduction}

Little is known about the biology surrounding decrements in cardiorespiratory (CR) fitness after stroke, but evidence has gradually begun to track the damage caused to multiple physiological systems by stroke-related chronic inactivity [18]. Collectively, these changes negatively impact morbidity and mortality prospects and contribute to reduced quality of life [9]. Because CR fitness is a measure that quantifies the ability of the heart, lungs, blood vessels, and skeletal muscles to work together to deliver oxygen and remove metabolic byproducts during exercise, it is indirectly reflective of broad categories of cardiovascular, metabolic, and functional health. Most often, CR fitness is measured using a metabolic cart for gas analysis and exercise equipment (e.g., treadmill, recumbent stepper, or cycle ergometer) to determine peak oxygen-consuming capacity $\left(\mathrm{VO}_{2}\right.$ peak) and is quantified during exercise to complete exhaustion [10-16].

CR fitness varies according to age, gender, physical activity levels, body composition, and the absence or presence of chronic disease or disability. In the poststroke population, the literature suggests that CR fitness is reduced by as much as $50 \%$ when compared to age-matched sedentary counterparts $[12,14]$. The extent of deterioration is associated with several clinically relevant biological correlates which were the focus of this review.

It remains unclear whether reduced CR fitness after stroke is due primarily to premorbid conditions, direct effects of the stroke itself, or poststroke physical inactivity. All are likely contributors but understanding the relative 
contributions of each will require further research into biological/etiological mechanisms [17]. Whatever the cause, it is important to assess the capacity of stroke survivors to physiologically adapt in response to aggressive rehabilitation therapy interventions. Hence, this review also outlines some of the preliminary progress made in deciphering the physiological benefits of exercise training after stroke. Arriving at a better understanding of the cardiovascular, metabolic, and functional adaptations resulting from a variety of therapy protocols and how these contribute to improved CR fitness is especially important for healthcare providers, rehabilitation specialists, and others working towards the common goal of improving overall health and quality of life in this clinical population.

\section{Biological Consequences Contributing to Reduced CR Fitness after Stroke}

Sequelae of an upper motor neuron lesion include hemiparesis, reduced mobility, impaired balance and in coordination, and diminished proprioceptive feedback [17]. Secondary conditions such as changes in muscle physiology and inflammation $[5,6]$, impaired hemodynamic response $[1,3,8]$, altered metabolic health [18], and, to a lesser extent, respiratory dysfunctions [19] can also negatively influence daily activities and exercise performance. The neuromotor system relies on effective motor unit recruitment and efficient mechanical movement to sustain physical activity and prevent early fatigue $[11,20-22]$. Altered neurological input to the periphery and associated disuse profoundly alters skeletal muscle tissue composition in the paretic limb, thereby, contributing to reduced CR fitness and related health problems.

\subsection{Muscle Physiology after Stroke}

2.1.1. Tissue Composition. Major structural and molecular abnormalities have been observed in hemiparetic leg muscle [4-7] with serious implications for impairment of strength [23-25], insulin sensitivity [26, 27], mobility function [10, $11,25]$, and CR fitness $[10,13,14,16,28]$. In addition to severe unilateral muscle wasting and increased intramuscular fat after stroke [7], there is a dramatic shift towards a higher proportion of fast twitch muscle fibers $[4,6]$, which are more insulin resistant and fatigue prone [29]. There is also preliminary evidence of a reduction in the number of capillaries per muscle fiber in paretic leg muscles with significant relationships between low capillary density and glucose intolerance in this population [30]. Finally, there is a nearly three-fold elevation in the expression of paretic leg muscle tumor necrosis factor-alpha (TNF- $\alpha$ ) [5], an inflammatory cytokine implicated in both muscle atrophy [31], and insulin resistance [32]. These pathological alterations in skeletal muscle represent novel targets for exercise rehabilitation strategies during the poststroke recovery period. Given the increasing numbers of elderly disabled by stroke [33], alternative rehabilitation strategies are needed to specifically address and reverse the effects of paresis on muscle tissue quantity and quality.
On the basis of physiological principles, there is little question that unilateral skeletal muscle changes after stroke contribute to worsening CR fitness and related health changes. A reduction in lean tissue, especially in the larger leg muscles, negatively affects $\mathrm{VO}_{2}$ and CR fitness [34]. Furthermore, muscle metabolism and the ability to perform specific activities are heavily influenced by fiber type. For example, the ability to successfully engage in endurance activities relies on aerobic metabolism which is primarily driven by slow myosin heavy chain (MHC) isoforms and type I muscle fibers while high-intensity, quick movements depend on the availability of fast myosin heavy chain isoforms and type II muscle fibers [35]. There is evidence that the increased proportion of fast myosin heavy chain isoforms in the paretic limb is inversely correlated with gait speed [6].

These fatigue prone muscle fibers negatively affect community ambulation through decreased gait efficiency and increased energy expenditure. This increased energy expenditure leads to chronic fatigue and can limit ability to perform activity after stroke [36]. Feelings of fatigue and tiredness may further inhibit performance of activities of daily living (ADLs) and instrumental activities of daily living (IADLs).

Sedentary, nondisabled individuals expend approximately $10.5 \mathrm{~mL}$ of oxygen $/ \mathrm{kg} / \mathrm{min}$ (3 metabolic equivalents, METS) during light IADLs and about 17.5 of oxygen $/ \mathrm{kg} / \mathrm{min}$ ( 5 METs) during heavy IADLs and are able to reach a maximum of 8-10 METS [37]. In contrast, people after stroke are only able to reach a maximum of 4-5 METS, making higher level ADLs impossible and lower level ADLs unsustainable [38]. A vicious cycle results when feelings of fatigue during daily activities further reduce activity participation, thereby, compounding CR fitness decline.

2.1.2. Proinflammatory Markers and Pathways. Beyond localized up-regulation of inflammatory markers in paretic skeletal muscle, there are also systemic changes in circulating levels with disabling conditions. Specifically, circulating cytokinessuch as TNF-alpha and IL-6, have been shown to increase with acute myocardial infarction, heart failure, and obesity [39-41]. Elevated levels of proinflammatory markers have also been reported after stroke [42-44] and have been strongly associated with larger infarct size and poor outcomes (i.e., early neurological decline) [44, 45]. Increases in oxidative stress are purported to interfere with vascular function $[40,46,47]$ and other aspects of physiology relevant to CR fitness and metabolic health. New onset of hypertension has been reported in individuals after an acute stroke with elevated levels of proinflammatory markers (TNF alpha, IL-6, and VCAM-1) [45]. This suggests that elevated levels of proinflammatory markers may alter peripheral biological mechanisms such as those associated with the endothelial nitric oxide system, contributing to increased vascular resistance, and negatively affecting participation in rehabilitation or adaptive capacity. However, the pathogenesis for the potential relationship between the inflammatory markers and impaired endothelial function after acute stroke is still unclear. Although a detailed description of complex cytokine networks in the context of general health and health 
improvement is beyond the scope of this brief review, a more detailed account of this subject is provided in a recent review by Ploeger et al. [48]. Importantly, the causes behind elevated circulating cytokines are complex, and there are gaps in our knowledge about how to intervene against chronic inflammatory disease in stroke and beyond [48].

Altered Glucose Metabolism after Stroke. Beyond strokeinduced changes to paretic side tissue composition secondary to altered neurological input, sedentary living and reduced CR fitness also partially contribute to a severe decline in metabolic status. Specifically, insulin resistance and glucose intolerance are highly prevalent after stroke [26, 27], leading to progressive cardiovascular disease risks [49] and predisposition to recurrent stroke [50].

Kernan et al. originally identified a high prevalence of insulin resistance during the subacute stroke recovery period [26]. Subsequent findings in chronic stroke [27] revealed a $77 \%$ prevalence of abnormal glucose metabolism. This is clinically relevant given that impaired glucose tolerance and diabetes prospectively predict two- and three-fold increased risk for recurrent cerebrovascular events, respectively [50]. Prospective studies showed that fasting hyperinsulinemia [51] and postload insulin areas during an oral glucose tolerance test (OGTT) [52] predicted risk of future stroke and cardiovascular events. Notably, a large Scandinavian study showed that those in the highest quintile of postload insulin area had a greater than two-fold relative risk of stroke than those in the lowest quintile of insulin area [52]. Thus, epidemiologic research based upon surrogate measures of insulin sensitivity provides powerful evidence that insulin resistance is strongly associated with vascular event risk and recurrent stroke. Generally, physical inactivity is a wellrecognized contributor to altered glucose metabolism and insulin sensitivity in all aging populations [53] and may play a particularly large role in stroke survivors [26, 27].

\subsection{Cardiovascular Regulation after Stroke}

2.2.1. Autonomic Control of Cardiac Function. The central nervous system (parasympathetic and sympathetic branches) regulates heart rate, cardiac contractility, blood pressure, and vasomotor tone of the blood vessels. Impairments related to autonomic control of blood flow and cardiac regulation can occur after stroke, specifically if the stroke occurs around the parietal and insular cortex [54-56]. One study reported that those individuals with left insular stroke had an increase in cardiac events such as heart failure within one year after stroke [57]. These cardiac complications could have significant effects for cardiac function during activity and exercise. It is well known that people post-stroke have lower heart rates and oxygen consumption at peak effort during a graded exercise test when compared to healthy sedentary age-matched peers $[12,14]$. This may be a result of impaired autonomic control of the cardiovascular system in addition to pharmacologic therapy (beta blockers).

2.2.2. Blood Flow and Vascular Function. Blood flow distribution is governed by central cardiovascular command (parasympathetic/sympathetic activity) [54] and peripheral mechanisms, such as metabolic demands, peripheral resistance, and changes in pressure $[55,56]$. Changes in either central or peripheral regulation can interrupt normal vascular function. Stroke-related changes in the brain, specifically in areas that regulate autonomic function, can have significant implications for blood pressure control and cardiac function during the acute phase of stroke recovery $[57,58]$.

In chronic stroke, blood flow in the paretic leg is significantly lower at rest [1-4] and during exercise [4], when compared to the nonparetic limb. These unique unilateral adaptations, not observed in nondisabled young and older adults, can influence performance of ADLs and quality of life $[59,60]$. Research suggested that reductions in blood flow occur secondary to decreased levels of physical activity $[59,61]$, which can affect blood flow velocity, endothelial function, and arterial diameter. A recent study determined that vascular remodeling in the femoral artery occurs in the paretic lower extremity after stroke [2]. The femoral artery diameter and blood flow velocity were significantly reduced in the paretic limb when compared to the nonparetic limb. The femoral artery wall thickness was also significantly greater in the paretic limb, potentially contributing to impaired flexibility of the vessel wall to vasodilate during activity to allow for adequate blood and oxygen delivery.

Most recently, interhemispheric differences in blood flow velocity (BFV) of the middle cerebral artery (MCA) have been shown [62]. The MCA BFV on the ipsilesional side was substantially lower than the contralesional vessel, suggesting that systemic vascular deterioration extends to the brain. More work is needed to determine how systemic and cerebral vascular functions interrelate and the systemic consequences of each phenomenon.

Respiratory Function after Stroke. Although not all patients after stroke have overt pulmonary disease [63], respiration may be compromised as a direct result of the stroke itself (particularly brain stem stroke), associated complications (e.g., weakness of respiratory muscles, impaired breathing mechanics), comorbidities (e.g., chronic obstructive pulmonary disease, cardiovascular dysfunction), or lifestyle factors (e.g., physical inactivity high incidence of smoking) [64]. The excessive fatigue experienced by some people after stroke may be partly due to respiratory insufficiency as manifested by low pulmonary diffusing capacity, ventilation-perfusion mismatching, or decreased lung volumes (e.g., vital capacity, total lung capacity, inspiratory and maximal inspiratory capacity, and expiratory reserve volume) $[65,66]$. Impaired breathing mechanics with restricted and paradoxical chest wall excursion and depressed diaphragmatic excursion have been also reported $[64,67]$. Expiratory dysfunction appears to be related to the extent of motor impairment (e.g., paresis of the hemi-diaphragm and intercostal and abdominal muscles) [65, 68-70]. Inspiratory limitations, manifested by reduced maximal inspiratory pressure [71], are related to reduced chest wall excursion secondary to the gradual development of rib cage contracture [72]. 
The physiologic impairments described above reduce the ventilatory reserve or the difference between the maximal available ventilation and the ventilation measured at the end of exercise [73] and contribute to low CR fitness levels in the stroke population. At peak exercise performance, people after stroke have significantly lower minute ventilation and tidal volume, but not respiratory rate, compared with control participants [74]. Reductions in lung volumes and chest wall movements can lead not only to decreased exercise endurance, shortness of breath, and risk of sedentary behavior but also increased risk of recurrent stroke [75]. Therefore, exercise interventions designed to improve respiratory muscle strength and pulmonary function should be encouraged.

\subsection{Exercise-Induced Adaptations in CR Fitness and Associated} Aspects of General Health after Stroke. Exercise is a potent physiological stimulus which could induce a wide range of adaptations. These adaptations include improved CR fitness, changes in vascular function and vascular morphology, reduced respiratory effort, and enhanced glucose metabolism and insulin sensitivity.

The capacity of the stroke population to make cardiorespiratory adaptations to aerobic exercise has been demonstrated in numerous training studies. Table 1 summarizes trials individuals in the subacute ( $<6$ months after stroke) and chronic ( $>6$ months post-stroke) stages of recovery. In these studies, the magnitude of change in peak $\mathrm{VO}_{2}$ (mean gain of $\sim 12.5 \%$ ) was comparable to the $10 \%$ to $30 \%$ improvements (reported for healthy, sedentary adults) [76, 77] and the $13 \%$ to $15 \%$ gains observed for participants in cardiac rehabilitation $[78,79]$. Even the relatively modest gains in CR fitness reported in some stroke exercise studies (e.g., $8 \%$ [80], $6 \%$ and [81]) may be sufficient to raise the anaerobic threshold, thereby, extending the time during which muscle contractions can be sustained with oxidative metabolism. Interventions which result in even small changes in aerobic capacity may be of clinical significance on the basis of where stroke survivors stand relative to the range of $\mathrm{VO}_{2}$ required for general ADLs [10,37]. Considering the degree to which $\mathrm{VO}_{2}$ peak levels have been compromised after stroke, even modest changes in CR fitness will have a greater impact on activities of daily living for stroke survivors than to their agematched healthy peers.

The considerable interindividual differences noted in most training studies are attributable to many factors, including severity of stroke, time since onset, variations in intensity and mode of training, and level of compliance with the exercise regimen $[11,21,22,90]$. In studies of people with stable coronary disease, considerable interindividual differences have been observed, of which only a small portion (about 11\%) have been attributed to recognized covariates such as initial fitness status and an even smaller percentage (about 5\%) to measurement errors [91, 92]. The most rapid improvements in exercise capacity tend to occur in previously sedentary people [93]. Further, it has long been acknowledged that the highest overall relative gains are usually seen in individuals with the lowest initial values of $\mathrm{VO}_{2}$ peak [94].

\subsection{Exercise-Induced Muscular Adaptations after Stroke}

2.4.1. General Adaptations. Several important studies reported that strength training, provided it is progressive and of adequate intensity, can be effective in combating the losses in muscle mass [95], muscle quality [96], and function [97] which typically occur with advancing age. Strength training results in significant muscle hypertrophy in both healthy elderly and frail elderly populations [95, 98]. Several studies also showed that strength training can affect adaptation in skeletal muscle fibers [99-101]. Strength training with high repetitions and a strong endurance component results in higher proportions of Type IIa (fast oxidative) [102, 103], and Type I [101, 104] myosin heavy chain muscle fiber types and is an effective stimulus for fiber hypertrophy in Type I, Type IIa, and Type IIx muscle fibers [101, 105, 106]. High repetition strength training also results in improved muscle capillarization in peripheral arterial disease patients [99] and in healthy populations [107]. Finally, there is evidence that TNF- $\alpha$ levels are successfully reduced with strength training in frail elderly humans [31].

2.4.2. Post-Stroke. Patients after stroke have been studied far less in the context of strength training. Of the few trials undertaken none have assessed the capacity of strength training to cause skeletal muscular adaptations. However, the results of a recently completed nonrandomized pilot study in chronic stroke [23] has showed that skeletal muscle hypertrophy accompanied by molecular adaptations occurred in both the paretic and nonparetic limbs. Pilot work suggested that functionally and metabolically relevant skeletal muscle tissue adaptations are possible in this population. There is now a randomized study underway to further test the impact of strength training on paretic limb skeletal muscle after stroke (Ivey, PI).

Metabolic Adaptations with Exercise in Stroke Survivors. Over the last decade, major advances have been made in the understanding of the effectiveness of exercise and lifestyle interventions to improve cardiometabolic health and prevent progression to diabetes in high-risk nonstroke populations. The Diabetes Prevention Program showed that lifestyle interventions based upon low-intensity exercise and weight loss were more effective than metformin (58\% versus $31 \%$ ) to prevent progression to diabetes in high-risk individuals, which occurs in $\sim 10 \%$ of controls annually by natural history [53]. Preliminary findings in chronic stroke survivors demonstrated that moderate intensity treadmill training reverses impaired glucose tolerance and type 2 diabetes status in $58 \%$ of cases [18]. The study investigated the effects of 6month moderate intensity treadmill training $(N=26)$ versus stretching exercises $(N=21)$ on insulin response during an OGTT and found significant reductions with treadmill training in fasting insulin areas compared to controls $(-23 \%$ versus $+9 \%, P<0.05)$. Changes in insulin area were inversely related to changes in $\mathrm{CR}$ fitness by $\mathrm{VO}_{2}$ peak in the two groups combined $(r=-0.34, P<0.05)$, but not to body weight or fat mass [18]. This suggested that greater improvements in $\mathrm{VO}_{2}$ peak, as with higher intensity training, may 
TABLE 1: Cardiorespiratory adaptations to aerobic training after stroke.

\begin{tabular}{|c|c|c|c|c|c|c|}
\hline Mode & No. of subjects & $\begin{array}{c}\text { Program } \\
\text { duration } \\
\text { weeks }\end{array}$ & $\begin{array}{l}\text { Frequency } \\
\text { x/week }\end{array}$ & $\begin{array}{l}\text { Session duration } \\
\text { minutes }\end{array}$ & Intensity & $\begin{array}{c}\text { Change in peak } \\
\mathrm{VO}_{2} \%\end{array}$ \\
\hline \multicolumn{7}{|c|}{ Subacute stroke ( $<6$ months after stroke) } \\
\hline Cycle ergo meter [82] & $\begin{array}{l}\text { E: } 44 \\
\text { C: } 48\end{array}$ & 12 & 3 & $20-30$ & $40 \mathrm{rpm}$ & $\begin{array}{c}\mathrm{E}:+9 \\
\mathrm{C}:+0.5\end{array}$ \\
\hline Treadmill $[83]$ & $\begin{array}{l}\mathrm{E}: 6 \\
\mathrm{C}: 6\end{array}$ & 26 & 5 & 20 & NR & $\begin{array}{l}\mathrm{E}:+35 \\
\mathrm{C}:+1\end{array}$ \\
\hline Cycle ergo meter [21] & $\begin{array}{l}\text { E: } 23 \\
\text { C: } 22\end{array}$ & $3-4$ & 3 & 30 & $50-75 \%$ peak $\mathrm{VO}_{2}$ & $\begin{array}{l}\mathrm{E}:+13 \\
\mathrm{C}:+8\end{array}$ \\
\hline \multicolumn{7}{|c|}{ Chronic stroke ( $>6$ months after stroke) } \\
\hline Cycleergometer [84] & $\begin{array}{l}\text { E: } 37 \\
\text { C: } 24\end{array}$ & 26 & 3 & $10-20$ & $40-50 \%$ HRR & $\begin{array}{l}\mathrm{E}:+18 \\
\mathrm{C}:-3\end{array}$ \\
\hline Cycleergometer [85] & $\begin{array}{l}\text { E: } 24 \\
\text { C: } 24\end{array}$ & 8 & 2 & 20 & $50-60 \%$ HRR & $\begin{array}{l}E:+13 \\
C:-3\end{array}$ \\
\hline Treadmill [18] & $\begin{array}{l}\text { E: } 26 \\
\text { C: } 20\end{array}$ & 26 & 3 & 40 & 60-70\% HRR & $\begin{array}{l}E:+15 \\
C:-3\end{array}$ \\
\hline $\begin{array}{l}\text { E1: Mod intensity [86] } \\
\text { E2: Low intensity }\end{array}$ & $\begin{array}{l}\text { E1: } 18 \\
\text { E2: } 19 \\
\text { C: } 18\end{array}$ & 14 & 3 & $30-60$ & $\begin{array}{l}\text { E1: } 50-69 \% \text { HRR } \\
\text { E2: }<50 \% \text { HRR }\end{array}$ & $\begin{array}{l}\mathrm{E} 1:+4 \\
\mathrm{E} 2:+6 \\
\mathrm{C}:-3\end{array}$ \\
\hline $\begin{array}{l}\text { Treadmill + strengthening } \\
\text { [87] }\end{array}$ & $\mathrm{E}: 14$ & 12 & 5 & 90 & $80 \%$ HR max & E: +19 \\
\hline Treadmill [81] & $\mathrm{E}: 20^{*}$ & 4 & $2-5$ & NR & $\begin{array}{l}80-85 \% \text { HR max } \\
\quad \text { or RPE } 17\end{array}$ & $\begin{array}{l}\text { Immediate: }+6 \\
\text { Delayed: }+6\end{array}$ \\
\hline Cycle ergometer [85] & $\begin{array}{l}\text { E: } 19 \\
\text { C: } 23\end{array}$ & 10 & 3 & 30 & $50-70 \mathrm{rpm}$ & $\begin{array}{l}\mathrm{E}:+13 \\
\mathrm{C}:+1\end{array}$ \\
\hline Aerobic exercise [80] & E: 29 & 12 & 3 & 30 & HR at RER of 1.0 & $\mathrm{E}:+8$ \\
\hline Treadmill [13] & E: 23 & 26 & 3 & 20 & $<60 \%$ HRR & $\mathrm{E}:+10$ \\
\hline Aerobic exercise [88] & $\begin{array}{l}\text { E: } 32 \\
\text { C: } 31\end{array}$ & 19 & 3 & 60 & $<80 \%$ HRR & $\begin{array}{l}\mathrm{E}:+9 \\
\mathrm{C}:+1\end{array}$ \\
\hline Water based [89] & $\begin{array}{l}\text { E: } 7 \\
\text { C: } 5\end{array}$ & 8 & 3 & 30 & $<80 \%$ HRR & $\begin{array}{l}\mathrm{E}:+23 \\
\mathrm{C}:+3\end{array}$ \\
\hline
\end{tabular}

E: Experimental; C: control; rpm: revolutions per minute; HRR: heart rate reserve; *crossover design; NR: not reported; RPE: rating of perceived exertion; RER: respiratory exchange quotient.

produce even greater improvements in insulin sensitivity. These preliminary findings have implications for diabetes prevention after stroke and warrant further investigation in the larger context of improving general health and function in this population.

Vascular Adaptations with Exercise after Stroke. During exercise, the arterial wall is chronically exposed to increased blood flow, and the vessel diameter expands to accommodate a larger volume of flow $[55,56]$. However, as with the above outcome categories, vascular adaptations to exercise after exercise stroke remain only partially understood, with initial experiments providing encouraging preliminary results. First, the group observed vascular changes after a unilateral training program that focused on exercising only the paretic leg. Beyond demonstrating increased functional performance and strength in the paretic limb with this intervention, there were also substantial vascular changes on the paretic side with the potential for altering regional and systemic physiological health [3]. Specifically, four weeks of unilateral leg training improved femoral artery blood flow and diameter [3]. More recently, treadmill training over six months has resulted in significantly improved resting and hyperemic blood flow in the paretic and the non-paretic lower extremities, when compared to elements of conventional stroke rehabilitation [8]. Briefly, treadmill training increased both resting and reactive hyperemic blood flow in the paretic limb by $25 \%$ compared to decreases in the control group $(P<0.001$, between groups). Similarly, non-paretic leg blood flow was significantly improved with tread mill training compared to controls $(P<0.001)$. CR fitness $\left(\mathrm{VO}_{2}\right.$ peak) improved by $18 \%$ with tread mill training and decreased by $4 \%$ in control $(P<0.01$, between groups), and there was a significant relationship between blood flow change and peak fitness change for the group as a whole $(r=0.30, P<0.05)$. There has been also recently published evidence showing that treadmill exercise training can have a positive impact on cerebral vasomotor function in both hemispheres, particularly in those not taking statin medication [62]. These data provided the first evidence of exercise-induced cerebral vasomotor reactivity 
improvements in stroke survivors, implying a protective mechanism against recurrent stroke and other brain-related disorders.

Respiratory Adaptations. Although reduced respiratory function has been reported after stroke, therapeutic interventions aimed at improving respiratory muscle strength and function are extremely limited. Two recent randomized controlled trials have examined the effects of inspiratory muscle training (IMT) in people after stroke. One trial examined whether six weeks of inspiratory muscle training would produce significant improvements in cardiopulmonary function when compared to a 6-week intervention consisting of breathing techniques and also a control group [63]. The authors concluded that IMT produced significant improvements in pulmonary function variables and cardiopulmonary outcomes during peak exercise testing. These improvements translated into functional gains as observed by the Barthel Index and functional ambulation scores.

Britto et al. published findings from a double-blind randomized controlled trial in chronic stroke survivors [108]. Individuals were randomized to an 8-week home-based exercise training program using either (1) an inspiratory muscle trainer (IMT) with progressive increases in resistance or (2) an IMT without resistance. Results demonstrated significant improvements in respiratory function (maximal inspiratory pressure and inspiratory muscular endurance) for the experimental group but not the control group. Although the experimental group (IMT with resistance) was able to exercise at a higher workload for the functional performance test, these differences were not significantly different. More work is needed in this area to identify other biologic factors which precipitate respiratory decline, identify therapeutic interventions to improve breathing mechanics, and improve pulmonary function in those individuals post-stroke.

\subsection{Adaptations in Memory and Cognition after Exercise and Stroke}

2.5.1. Animal Models. Given the central importance of cognitive health to all aspects of functional and physiological health after stroke [109], researchers are now accumulating evidence related to how exercise impacts this outcome category. Over the past 15 years, progress has been made in understanding the influences of exercise on central nervous system functions (see reviews Kramer, 2007; Devine, 2009). Animal studies have demonstrated favorable effects of aerobic training on neural function through modulation of synaptic plasticity underlying neuroprotective and neuroadaptive processes [110]. For example, learning and memory were enhanced in rats after one week of voluntary wheel running [111], possibly through the upregulation of brain-derived neurotrophic factor (BDNF) $[112,113]$ or other growth factors, such as vascular endothelial growth factor [114]. In a rodent stroke model, treadmill exercise enhanced gene expression for BDNF and a corresponding reduction in brain infarct volume [115]. Similarly, exercise attenuated the effects of traumatic brain injury, again in a rodent model, through a BDNF-mediated mechanism [116].
These neuroplastic responses appear to be dose dependent [117].

2.5.2. Human Models. Human studies have begun to reinforce the findings of the earlier animal work. Evidence of a causal relationship between exercise training and improved cognition has been reported in older adults without known cognitive impairment $[118,119]$ and in people with cardiovascular disease [120]. Quaney and colleagues [121] provided the first preliminary evidence on the effects of exercise training on cognitive executive function and motor learning in chronic stroke survivors. After an 8-week cycle ergometry exercise program, significant improvements were found in measures of information processing and complex motor learning tasks [121].

\section{Conclusions}

Reduced CR fitness after stroke is well documented with clinically relevant physiologic consequences. Although the precise mechanisms and the consequences of the severe reduction in CR fitness have not been fully elucidated, preliminary evidence points to several noteworthy biological correlates. For example, maladaptive changes to the tissues of the paretic side may both contribute to and be compounded by reductions in CR fitness. These include negative unilateral changes in muscle mass, intramuscular fat, muscle fiber type distribution, hemodynamic function, capillary density, and inflammatory markers. Further, there are systemic disturbances to metabolism and respiration which are exacerbated due to the presence of sedentary living and accompanying CR fitness decline. The evidence in the literature suggests that maladaptive physiologic changes have been observed in the paretic lower limb and these may contribute to the low CR fitness found in people post-stroke.

Exercise training has been shown to be a potent stimulus for improving CR fitness and associated physiological outcomes in both stroke and nonstroke aging populations. Changes in $\mathrm{VO}_{2}$ peak, muscle tissue quantity, muscle biology, tissue inflammation, pulmonary function, systemic metabolism, and cognition have all been reported in various elderly and disabled subgroups. Although the body of evidence for exercise-induced adaptation in stroke is limited, great progress has been made over the last decade to show that stroke survivors maintain their capacity to adapt and are capable of performing exercise at levels not previously thought possible. Further work is needed to determine the effects of exercise on attenuating inflammatory responses and improving tissue composition after stroke. While a limited number of exercise training studies have increased pulmonary performance after stroke, it is evident that continued work in this area is needed to improve functional and cardiorespiratory outcomes. Finally, larger randomized research studies aimed at effective exercise prescription and informing best practice in stroke rehabilitation are essential to the advancement of stroke recovery. 


\section{References}

[1] F. M. Ivey, A. W. Gardner, C. L. Dobrovolny, and R. F. Macko, "Unilateral impairment of leg blood flow in chronic stroke patients," Cerebrovascular Diseases, vol. 18, no. 4, pp. 283 $289,2004$.

[2] S. A. Billinger and P. M. Kluding, "Use of doppler ultrasound to assess femoral artery adaptations in the hemiparetic limb in people with stroke," Cerebrovascular Diseases, vol. 27, no. 6, pp. 552-558, 2009.

[3] S. A. Billinger, B. J. Gajewski, L. X. Guo, and P. M. Kluding, "Single limb exercise induces femoral artery remodeling and improves blood flow in the hemiparetic leg poststroke," Stroke, vol. 40, no. 9, pp. 3086-3090, 2009.

[4] S. Landin, L. Hagenfeldt, B. Saltin, and J. Wahren, "Muscle metabolism during exercise in hemiparetic patients," Clinical Science and Molecular Medicine, vol. 53, no. 3, pp. 257-269, 1977.

[5] C. E. Hafer-Macko, S. Yu, A. S. Ryan, F. M. Ivey, and R. F. Macko, "Elevated tumor necrosis factor- $\alpha$ in skeletal muscle after stroke," Stroke, vol. 36, no. 9, pp. 2021-2023, 2005.

[6] P. G. De Deyne, C. E. Hafer-Macko, F. M. Ivey, A. S. Ryan, and R. F. Macko, "Muscle molecular phenotype after stroke is associated with gait speed," Muscle and Nerve, vol. 30, no. 2, pp. 209-215, 2004.

[7] A. S. Ryan, C. L. Dobrovolny, G. V. Smith, K. H. Silver, and R. F. Macko, "Hemiparetic muscle atrophy and increased intramuscular fat in stroke patients," Archives of Physical Medicine and Rehabilitation, vol. 83, no. 12, pp. 1703-1707, 2002.

[8] F. M. Ivey, C. E. Hafer-Macko, A. S. Ryan, and R. F. MacKo, "Impaired leg vasodilatory function after stroke: adaptations with treadmill exercise training," Stroke, vol. 41, no. 12, pp. 2913-2917, 2010.

[9] N. F. Gordon, M. Gulanick, F. Costa et al., "Physical activity and exercise recommendations for stroke survivors: an American Heart Association Scientific Statement from the Council on Clinical Cardiology, Subcommittee on Exercise, Cardiac Rehabilitation, and Prevention; the Council on Cardiovascular Nursing; the Council on Nutrition, Physical Activity, and Metabolism; and the Stroke Council," Circulation, vol. 109, no. 16, pp. 2031-2041, 2004.

[10] F. M. Ivey, R. F. Macko, A. S. Ryan, and C. E. Hafer-Macko, "Cardiovascular health and fitness after stroke," Topics in Stroke Rehabilitation, vol. 12, no. 1, pp. 1-16, 2005.

[11] R. F. Macko, C. A. DeSouza, L. D. Tretter et al., "Treadmill aerobic exercise training reduces the energy expenditure and cardiovascular demands of hemiparetic gait in chronic stroke patients: a preliminary report," Stroke, vol. 28, no. 2, pp. 326330, 1997.

[12] R. F. Macko, L. I. Katzel, A. Yataco et al., "Low-velocity graded treadmill stress testing in hemiparetic stroke patients," Stroke, vol. 28, no. 5, pp. 988-992, 1997.

[13] R. F. Macko, G. V. Smith, C. L. Dobrovolny, J. D. Sorkin, A. P. Goldberg, and K. H. Silver, "Treadmill training improves fitness reserve in chronic stroke patients," Archives of Physical Medicine and Rehabilitation, vol. 82, no. 7, pp. 879-884, 2001.

[14] M. J. MacKay-Lyons and L. Makrides, "Exercise capacity early after stroke," Archives of Physical Medicine and Rehabilitation, vol. 83, no. 12, pp. 1697-1702, 2002.

[15] S. A. Billinger, B. Y. Tseng, and P. M. Kluding, "Modified total-body recumbent stepper exercise test for assessing peak oxygen consumption in people with chronic stroke," Physical Therapy, vol. 88, no. 10, pp. 1188-1195, 2008.
[16] S. Billinger, L. X. Guo, P. S. Pohl, and P. M. Kluding, "Single limb exercise: pilot study of physiological and functional responses to forced use of the hemiparetic lower extremity," Topics in Stroke Rehabilitation, vol. 17, no. 2, pp. 128-139, 2010.

[17] M. J. MacKay-Lyons and J. Hewlett, "Exercise capacity and cardiovascular adaptations to aerobic training early after stroke," Topics in Stroke Rehabilitation, vol. 12, no. 1, pp. 3144, 2005.

[18] F. M. Ivey, A. S. Ryan, C. E. Hafer-Macko, A. P. Goldberg, and R. F. Macko, "Treadmill aerobic training improves glucose tolerance and indices of insulin sensitivity in disabled stroke survivors: a preliminary report," Stroke, vol. 38, no. 10, pp. 2752-2758, 2007.

[19] C. L. Rochester and V. Mohsenin, "Respiratory complications of stroke," Seminars in Respiratory and Critical Care Medicine, vol. 23, no. 3, pp. 248-260, 2002.

[20] B. Y. Tseng, S. A. Billinger, B. J. Gajewski, and P. M. Kluding, "Exertion fatigue and chronic fatigue are two distinct constructs in people post-stroke," Stroke, vol. 41, no. 12, pp. 2908-2912, 2010.

[21] A. Tang, K. M. Sibley, S. G. Thomas et al., "Effects of an aerobic exercise program on aerobic capacity, spatiotemporal gait parameters, and functional capacity in subacute stroke," Neurorehabilitation and Neural Repair, vol. 23, no. 4, pp. 398406, 2009.

[22] R. F. Macko, F. M. Ivey, L. W. Forrester et al., "Treadmill exercise rehabilitation improves ambulatory function and cardiovascular fitness in patients with chronic stroke: a randomized, controlled trial," Stroke, vol. 36, no. 10, pp. 22062211, 2005.

[23] A. S. Ryan, F. M. Ivey, S. Prior, G. Li, and C. HaferMacko, "Skeletal muscle hypertrophy and muscle myostatin reduction after resistive training in stroke survivors," Stroke, vol. 42, no. 2, pp. 416-420, 2011.

[24] C. Maria Kim and J. J. Eng, "The relationship of lowerextremity muscle torque to locomotor performance in people with stroke," Physical Therapy, vol. 83, no. 1, pp. 49-57, 2003.

[25] R. W. Bohannon, "Knee extension strength and body weight determine sit-to-stand independence after stroke," Physiotherapy Theory and Practice, vol. 23, no. 5, pp. 291-297, 2007.

[26] W. N. Kernan, S. E. Inzucchi, C. M. Viscoli et al., "Impaired insulin sensitivity among nondiabetic patients with a recent TIA or ischemic stroke," Neurology, vol. 60, no. 9, pp. 14471451, 2003.

[27] F. M. Ivey, A. S. Ryan, C. E. Hafer-Macko et al., "High prevalence of abnormal glucose metabolism and poor sensitivity of fasting plasma glucose in the chronic phase of stroke," Cerebrovascular Diseases, vol. 22, no. 5-6, pp. 368-371, 2006.

[28] J. O. Kelly, S. L. Kilbreath, G. M. Davis, B. Zeman, and J. Raymond, "Cardiorespiratory fitness and walking ability in subacute stroke patients," Archives of Physical Medicine and Rehabilitation, vol. 84, no. 12, pp. 1780-1785, 2003.

[29] J. R. Daugaard and E. A. Richter, "Relationship between muscle fibre composition, glucose transporter protein 4 and exercise training: possible consequences in non-insulindependent diabetes mellitus," Acta Physiologica Scandinavica, vol. 171, no. 3, pp. 267-276, 2001.

[30] S. J. Prior, M. J. Mckenzie, L. J. Joseph et al., "Reduced skeletal muscle capillarization and glucose intolerance," Microcirculation, vol. 16, no. 3, pp. 203-212, 2009.

[31] J. S. Greiwe, C. Bo, D. C. Rubin, K. E. Yarasheski, and C. F. Semenkovich, "Resistance exercise decreases skeletal muscle 
tumor necrosis factor $\alpha$ in frail elderly humans," FASEB Journal, vol. 15, no. 2, pp. 475-482, 2001.

[32] M. Saghizadeh, J. M. Ong, W. T. Garvey, R. R. Henry, and P. A. Kern, "The expression of TNF $\alpha$ by human muscle: relationship to insulin resistance," Journal of Clinical Investigation, vol. 97, no. 4, pp. 1111-1116, 1996.

[33] V. L. Roger, A. S. Go, D. M. Lloyd-Jones et al., "Heart disease and stroke statistics-2011 update: a report from the American Heart Association," Circulation, vol. 123, no. 4, pp. e18-e209, 2011.

[34] A. S. Ryan, C. L. Dobrovolny, K. H. Silver, G. V. Smith, and R. F. Macko, "Cardiovascular fitness after stroke: role of muscle mass and gait deficit severity," Journal of Stroke and Cerebrovascular Diseases, vol. 9, no. 4, pp. 185-191, 2000.

[35] G. A. Brooks, T. D. Fahey, and K. M. Baldwin, "Neurons, motor unit recruitment, and integrative control of movement," in Exercise Physiology: Human Bioenergetics and Its Applications, E Barrosse, Ed., pp. 396-429, McGraw Hill, Boston, Mass, USA, 2005.

[36] K. Michael, "Fatigue and stroke," Rehabilitation Nursing, vol. 27, no. 3, pp. 89-103, 2002.

[37] B. E. Ainsworth, W. L. Haskell, M. C. Whitt et al., "Compendium of physical activities: an update of activity codes and MET intensities," Medicine and Science in Sports and Exercise, vol. 32, no. 9, pp. S498-S504, 2000.

[38] F. M. Ivey, C. E. Hafer-Macko, and R. F. Macko, "Exercise rehabilitation after stroke," NeuroRx, vol. 3, no. 4, pp. 439450, 2006.

[39] I. Kovacs, J. Toth, J. Tarjan, and A. Koller, "Correlation of flow mediated dilation with inflammatory markers in patients with impaired cardiac function. Beneficial effects of inhibition of ACE," European Journal of Heart Failure, vol. 8, no. 5, pp. 451-459, 2006.

[40] R. Ferrari, T. Bachetti, L. Agnoletti, L. Comini, and S. Curello, "Endothelial function and dysfunction in heart failure," European Heart Journal, vol. 19, pp. G41-G47, 1998.

[41] R. Gomez, F. Lago, J. Gomez-Reino, C. Dieguez, and O. Gualillo, "Adipokines in the skeleton: influence on cartilage function and joint degenerative diseases," Journal of Molecular Endocrinology, vol. 43, no. 1, pp. 11-18, 2009.

[42] A. Hassan, K. Gormley, M. O’Sullivan et al., "Endothelial nitric oxide gene haplotypes and risk of cerebral small-vessel disease," Stroke, vol. 35, no. 3, pp. 654-659, 2004.

[43] S. K. Nadar, G. Y. H. Lip, K. W. Lee, and A. D. Blann, "Circulating endothelial cells in acute ischaemic stroke," Thrombosis and Haemostasis, vol. 94, no. 4, pp. 707-712, 2005.

[44] M. Castellanos, J. Castillo, M. M. García et al., "Inflammationmediated damage in progressing lacunar infarctions a potential therapeutic target," Stroke, vol. 33, no. 4, pp. 982987, 2002.

[45] M. Rodríguez-Yáñez, M. Castellanos, M. Blanco et al., "Newonset hypertension and inflammatory response/poor outcome in acute ischemic stroke," Neurology, vol. 67, no. 11, pp. 1973-1978, 2006.

[46] A. Blum and H. Miller, "Role of cytokines in heart failure," American Heart Journal, vol. 135, no. 2, part 1, pp. 181-186, 1998.

[47] P. Aukrust, T. Ueland, E. Lien et al., "Cytokine network in congestive heart failure secondary to ischemic or idiopathic dilated cardiomyopathy," American Journal of Cardiology, vol. 83, no. 3, pp. 376-382, 1999.
[48] H. E. Ploeger, T. Takken, M. H. de Greef, and B. W. Timmons, "The effects of acute and chronic exercise on inflammatory markers in children and adults with a chronic inflammatory disease: a systematic review," Exercise Immunology Review, vol. 15, pp. 6-41, 2009.

[49] J. Jeppesen, T. W. Hansen, S. Rasmussen, H. Ibsen, C. TorpPedersen, and S. Madsbad, "Insulin resistance, the metabolic syndrome, and risk of incident cardiovascular disease. A population-based study," Journal of the American College of Cardiology, vol. 49, no. 21, pp. 2112-2119, 2007.

[50] S. E. Vermeer, W. Sandee, A. Algra, P. J. Koudstaal, L. J. Kappelle, and D. W. J. Dippel, "Impaired glucose tolerance increases stroke risk in nondiabetic patients with transient ischemic attack or minor ischemic stroke," Stroke, vol. 37, no. 6, pp. 1413-1417, 2006.

[51] H. M. Lakka, T. A. Lakka, J. Tuomilehto, J. Sivenius, and J. T. Salonen, "Hyperinsulinemia and the risk of cardiovascular death and acute coronary and cerebrovascular events in men: the Kuopio Ischaemic Heart Disease Risk Factor Study," Archives of Internal Medicine, vol. 160, no. 8, pp. 1160-1168, 2000.

[52] M. Pyörälä, H. Miettinen, M. Laakso, and K. Pyörälä, "Hyperinsulinemia and the risk of stroke in healthy middle-aged men: the 22-year follow-up results of the Helsinki Policemen Study," Stroke, vol. 29, no. 9, pp. 1860-1866, 1998.

[53] W. C. Knowler, E. Barrett-Connor, S. E. Fowler et al., "Reduction in the incidence of type 2 diabetes with lifestyle intervention or metformin," New England Journal of Medicine, vol. 346, no. 6, pp. 393-403, 2002.

[54] J. W. Williamson, P. J. Fadel, and J. H. Mitchell, "New insights into central cardiovascular control during exercise in humans: a central command update," Experimental Physiology, vol. 91, no. 1, pp. 51-58, 2006.

[55] D. E. Mohrman and L. J. Heller, Cardiovascular Physiology, Lange Medical Books, McGraw-Hill, New York, NY, USA, 2006.

[56] H. L. Gerrits, A. de Haan, A. J. Sargeant, H. van Langen, and M. T. Hopman, "Peripheral vascular changes after electrically stimulated cycle training in people with spinal cord injury," Archives of Physical Medicine and Rehabilitation, vol. 82, no. 6, pp. 832-839, 2001.

[57] L. A. Henderson, C. A. Richard, P. M. Macey et al., "Functional magnetic resonance signal changes in neural structures to baroreceptor reflex activation," Journal of Applied Physiology, vol. 96, no. 2, pp. 693-703, 2004.

[58] F. Rincon, M. Dhamoon, Y. Moon et al., "Stroke location and association with fatal cardiac outcomes: Northern Manhattan study (NOMAS)," Stroke, vol. 39, no. 9, pp. 2425-2431, 2008.

[59] M. W. P. Bleeker, P. C. E. De Groot, F. Poelkens, G. A. Rongen, P. Smits, and M. T. E. Hopman, "Vascular adaptation to 4 wk of deconditioning by unilateral lower limb suspension," American Journal of Physiology-Heart and Circulatory Physiology, vol. 288, no. 4, pp. H1747-H1755, 2005.

[60] M. W. P. Bleeker, P. C. E. De Groot, G. A. Rongen et al., "Vascular adaptation to deconditioning and the effect of an exercise countermeasure: results of the Berlin Bed Rest study," Journal of Applied Physiology, vol. 99, no. 4, pp. 1293-1300, 2005.

[61] F. A. Dinenno, P. P. Jones, D. R. Seals, and H. Tanaka, "Limb blood flow and vascular conductance are reduced with age in healthy humans: relation to elevations in sympathetic 
nerve activity and declines in oxygen demand," Circulation, vol. 100, no. 2, pp. 164-170, 1999.

[62] F. M. Ivey, A. S. Ryan, C. E. Hafer-Macko, and R. F. Macko, "Improved cerebral vasomotor reactivity after exercise training in hemiparetic stroke survivors," Stroke, vol. 42, no. 7, pp. 1994-2000, 2011.

[63] S. T. Sutbeyaz, F. Koseoglu, L. Inan, and O. Coskun, "Respiratory muscle training improves cardiopulmonary function and exercise tolerance in subjects with subacute stroke: a randomized controlled trial," Clinical Rehabilitation, vol. 24, no. 3, pp. 240-250, 2010.

[64] F. Vingerhoets and J. Bogousslavsky, "Respiratory dysfunction in stroke," Clinics in Chest Medicine, vol. 15, no. 4, pp. 729-737, 1994.

[65] E. J. Roth, "Heart disease in patients with stroke: incidence, impact, and implications for rehabilitation part 1: classification and prevalence," Archives of Physical Medicine and Rehabilitation, vol. 74, no. 7, pp. 752-760, 1993.

[66] A. Haas, H. A. Rusk, H. Pelosof, and J. R. Adam, "Respiratory function in hemiplegic patients," Archives of Physical Medicine and Rehabilitation, vol. 48, no. 4, pp. 174-179, 1967.

[67] A. R. Fugl-Meyer and G. Grimby, "Respiration in tetraplegia and in hemiplegia: a review," International Rehabilitation Medicine, vol. 6, no. 4, pp. 186-190, 1984.

[68] J. M. Annoni, D. Ackermann, and J. Kesselring, "Respiratory function in chronic hemiplegia," International Disability Studies, vol. 12, no. 2, pp. 78-80, 1990.

[69] T. Similowski, M. Catala, G. Rancurel, and J. P. Derenne, "Impairment of central motor conduction to the diaphragm in stroke," American Journal of Respiratory and Critical Care Medicine, vol. 154, no. 2, part 1, pp. 436-441, 1996.

[70] B. Lanini, R. Bianchi, I. Romagnoli et al., "Chest wall kinematics in patients with hemiplegia," American Journal of Respiratory and Critical Care Medicine, vol. 168, no. 1, pp. 109-113, 2003.

[71] L. F. Teixeira-Salmela, V. F. Parreira, R. R. Britto et al., "Respiratory pressures and thoracoabdominal motion in community-dwelling chronic stroke survivors," Archives of Physical Medicine and Rehabilitation, vol. 86, no. 10, pp. 1974-1978, 2005.

[72] A. R. Fugl-Meyer, H. Linderholm, and A. F. Wilson, "Restrictive ventilatory dysfunction in stroke: its relation to locomotor function," Scandinavian Journal of Rehabilitation Medicine, vol. 15, no. 9, pp. 118-124, 1983.

[73] T. J. Clark, S. Freedman, E. J. Campbell, and R. R. Winn, "The ventilatory capacity of patients with chronic airways obstruction," Clinical Science, vol. 36, no. 2, pp. 307-316, 1969.

[74] C. R. Tomczak, A. Jelani, R. G. Haennel, M. J. Haykowsky, R. Welsh, and P. J. Manns, "Cardiac reserve and pulmonary gas exchange kinetics in patients with stroke," Stroke, vol. 39, no. 11, pp. 3102-3106, 2008.

[75] J. van der Palen, T. D. Rea, T. A. Manolio et al., "Respiratory muscle strength and the risk of incident cardiovascular events," Thorax, vol. 59, no. 12, pp. 1063-1067, 2004.

[76] ACSM: American College of Sports Medicine Position Stand, "The recommended quantity and quality of exercise for developing and maintaining cardiorespiratory and muscular fitness, and flexibility in healthy adults," Medicine and Science in Sports and Exercise, vol. 30, no. 6, pp. 975-991, 1998.

[77] G. Samitz and N. Bachl, "Physical training programs and their effects on aerobic capacity and coronary risk profile in sedentary individuals. Design of a long-term exercise training program," Journal of Sports Medicine and Physical Fitness, vol. 31, no. 2, pp. 283-293, 1991.

[78] B. A. Franklin, I. Besseghini, and L. H. Golden, "Low intensity physical conditioning: effects on patients with coronary heart disease," Archives of Physical Medicine and Rehabilitation, vol. 59, no. 6, pp. 276-280, 1978.

[79] D. J. Mertens and T. Kavanagh, "Exercise training for patients with chronic atrial fibrillation," Journal of Cardiopulmonary Rehabilitation, vol. 16, no. 3, pp. 193-196, 1996.

[80] J. H. Rimmer, C. Braunschweig, K. Silverman, B. Riley, T. Creviston, and T. Nicola, "Effects of a short-term health promotion intervention for a predominantly African-American group of stroke survivors," American Journal of Preventive Medicine, vol. 18, no. 4, pp. 332-338, 2000.

[81] J. L. Moore, E. J. Roth, C. Killian, and T. G. Hornby, "Locomotor training improves daily stepping activity and gait efficiency in individuals poststroke who have reached a "plateau" in recovery," Stroke, vol. 41, no. 1, pp. 129-135, 2010.

[82] P. W. Duncan, S. Studenski, L. Richards et al., "Randomized clinical trial of therapeutic exercise in subacute stroke," Stroke, vol. 34, no. 9, pp. 2173-2180, 2003.

[83] I. Teixeira da Cunha Filho, P. A. C. Lim, H. Qureshy, H. Henson, T. Monga, and E. J. Protas, "A comparison of regular rehabilitation and regular rehabilitation with supported treadmill ambulation training for acute stroke patients," Journal of Rehabilitation Research and Development, vol. 38, no. 2, pp. 245-255, 2001.

[84] A. R. Luft, R. F. MacKo, L. W. Forrester et al., "Treadmill exercise activates subcortical neural networks and improves walking after stroke: a randomized controlled trial," Stroke, vol. 39, no. 12, pp. 3341-3350, 2008.

[85] O. Lennon, A. Carey, N. Gaffney, J. Stephenson, and C. Blake, "A pilot randomized controlled trial to evaluate the benefit of the cardiac rehabilitation paradigm for the non-acute ischaemic stroke population," Clinical Rehabilitation, vol. 22, no. 2, pp. 125-133, 2008.

[86] J. H. Rimmer, A. E. Rauworth, E. C. Wang, T. L. Nicola, and B. Hill, "A preliminary study to examine the effects of aerobic and therapeutic (nonaerobic) exercise on cardiorespiratory fitness and coronary risk reduction in stroke survivors," Archives of Physical Medicine and Rehabilitation, vol. 90, no. 3, pp. 407-412, 2009.

[87] J. R. Jørgensen, D. T. Bech-Pèdersen, P. Zeeman, J. Sørensen, L. L. Andersen, and M. Schönberger, "Effect of intensive outpatient physical training on gait performance and cardiovascular health in people with hemiparesis after stroke," Physical Therapy, vol. 90, no. 4, pp. 527-537, 2010.

[88] M. Y. C. Pang, J. J. Eng, and A. S. Dawson, "Relationship between ambulatory capacity and cardiorespiratory fitness in chronic stroke: influence of stroke-specific impairments," Chest, vol. 127, no. 2, pp. 495-501, 2005.

[89] K. S. Chu, J. J. Eng, A. S. Dawson, J. E. Harris, A. Ozkaplan, and S. Gylfadóttir, "Water-based exercise for cardiovascular fitness in people with chronic stroke: a randomized controlled trial," Archives of Physical Medicine and Rehabilitation, vol. 85, no. 6, pp. 870-874, 2004.

[90] J. S. Yates, S. Studenski, S. Gollub et al., "Bicycle ergometry in subacute-stroke survivors: feasibility, safety, and exercise performance," Journal of Aging and Physical Activity, vol. 12, no. 1, pp. 64-74, 2004. 
[91] P. A. Ades, M. L. Waldmann, W. L. Meyer et al., "Skeletal muscle and cardiovascular adaptations to exercise conditioning in older coronary patients," Circulation, vol. 94, no. 3, pp. 323-330, 1996.

[92] A. A. Ehsani, W. H. Martin III, G. W. Heath, and E. F. Coyle, "Cardiac effects of prolonged and intense exercise training in patients with coronary artery disease," American Journal of Cardiology, vol. 50, no. 2, pp. 246-254, 1982.

[93] R. J. Shephard, T. Rankinen, and C. Bouchard, "Test-retest errors and the apparent heterogeneity of training response," European Journal of Applied Physiology, vol. 91, no. 2-3, pp. 199-203, 2004.

[94] B. Saltin, "Physiological effects of physical conditioning," Medicine and Science in Sports and Exercise, vol. 1, pp. 50-56, 1969.

[95] F. M. Ivey, S. M. Roth, R. E. Ferrell et al., "Effects of age, gender, and myostatin genotype on the hypertrophic response to heavy resistance strength training," Journals of Gerontology-Series A Biological Sciences and Medical Sciences, vol. 55, no. 11, pp. M641-M648, 2000.

[96] F. M. Ivey, B. L. Tracy, J. T. Lemmer et al., "Effects of strength training and detraining on muscle quality: age and gender comparisons," Journals of Gerontology-Series A Biological Sciences and Medical Sciences, vol. 55, no. 3, pp. B152-B157, 2000.

[97] T. Manini, M. Marko, T. VanArnam et al., "Efficacy of resistance and task-specific exercise in older adults who modify tasks of everyday life," Journals of Gerontology-Series A Biological Sciences and Medical Sciences, vol. 62, no. 6, pp. 616-623, 2007.

[98] M. A. Fiatarone, E. C. Marks, N. D. Ryan, C. N. Meredith, L. A. Lipsitz, and W. J. Evans, "High-intensity strength training in nonagenarians. Effects on skeletal muscle," Journal of the American Medical Association, vol. 263, no. 22, pp. 30293034, 1990.

[99] M. R. McGuigan, R. Bronks, R. U. Newton et al., "Resistance training in patients with peripheral arterial disease: effects on myosin isoforms, fiber type distribution, and capillary supply to skeletal muscle," Journals of Gerontology-Series A Biological Sciences and Medical Sciences, vol. 56, no. 7, pp. B302-B310, 2001.

[100] A. I. Kryger and J. L. Andersen, "Resistance training in the oldest old: Consequences for muscle strength, fiber types, fiber size, and MHC isoforms," Scandinavian Journal of Medicine and Science in Sports, vol. 17, no. 4, pp. 422-430, 2007.

[101] G. F. Martel, S. M. Roth, F. M. Ivey et al., "Age and sex affect human muscle fiber adaptations to heave-resistance strength training," Experimental Physiology, vol. 91, no. 2, pp. 457464, 2005.

[102] C. T. Putman, X. Xu, E. Gillies, I. M. MacLean, and G. J. Bell, "Effects of strength, endurance and combined training on myosin heavy chain content and fibre-type distribution in humans," European Journal of Applied Physiology, vol. 92, no. 4-5, pp. 376-384, 2004.

[103] R. S. Hikida, R. S. Staron, F. C. Hagerman et al., "Effects of high-intensity resistance training on untrained older men. II. Muscle fiber characteristics and nucleo-cytoplasmic relationships," Journals of Gerontology-Series A Biological Sciences and Medical Sciences, vol. 55, no. 7, pp. B347-B354, 2000.

[104] U. Raue, B. Terpstra, D. L. Williamson, P. M. Gallagher, and S. W. Trappe, "Effects of short-term concentric vs. eccentric resistance training on single muscle fiber MHC distribution in humans," International Journal of Sports Medicine, vol. 26, no. 5, pp. 339-343, 2005.

[105] L. L. Andersen, G. Tufekovic, M. K. Zebis et al., "The effect of resistance training combined with timed ingestion of protein on muscle fiber size and muscle strength," Metabolism: Clinical and Experimental, vol. 54, no. 2, pp. 151-156, 2005.

[106] K. Häkkinen, W. J. Kraemer, A. Pakarinen et al., "Effects of heavy resistance/power training on maximal strength, muscle morphology, and hormonal response patterns in 6075-Year-old men and women," Canadian Journal of Applied Physiology, vol. 27, no. 3, pp. 213-231, 2002.

[107] P. A. Tesch, "Skeletal muscle adaptations consequent to longterm heavy resistance exercise," Medicine and Science in Sports and Exercise, vol. 20, no. 5, pp. S132-S134, 1988.

[108] R. R. Britto, N. R. Rezende, K. C. Marinho, J. L. Torres, V. F. Parreira, and L. F. Teixeira-Salmela, "Inspiratory muscular training in chronic stroke survivors: a randomized controlled trial," Archives of Physical Medicine and Rehabilitation, vol. 92, no. 2, pp. 184-190, 2011.

[109] N. J. Donovan, D. L. Kendall, S. C. Heaton, S. Kwon, C. A. Velozo, and P. W. Duncan, "Conceptualizing functional cognition in stroke," Neurorehabilitation and Neural Repair, vol. 22, no. 2, pp. 122-135, 2008.

[110] R. K. Dishman, H. -R. Berthoud, F. W. Booth et al., "Neurobiology of exercise," Obesity, vol. 14, no. 3, pp. 345-356, 2006.

[111] H. van Praag, G. Kempermann, and F. H. Gage, "Running increases cell proliferation and neurogenesis in the adult mouse dentate gyrus," Nature Neuroscience, vol. 2, no. 3, pp. 266-270, 1999.

[112] S. A. Neeper, F. Gómez-Pinilla, J. Choi, and C. W. Cotman, "Physical activity increases mRNA for brain-derived neurotrophic factor and nerve growth factor in rat brain," Brain Research, vol. 726, no. 1-2, pp. 49-56, 1996.

[113] S. Vaynman, Z. Ying, and F. Gomez-Pinilla, "Hippocampal BDNF mediates the efficacy of exercise on synaptic plasticity and cognition," European Journal of Neuroscience, vol. 20, no. 10, pp. 2580-2590, 2004.

[114] Y. H. Ding, X. D. Luan, J. Li et al., "Exercise-induced overexpression of angiogenic factors and reduction of ischemia/reperfusion injury in stroke," Current Neurovascular Research, vol. 1, no. 5, pp. 411-420, 2004.

[115] E. T. Ang, P. T. H. Wong, S. Moochhala, and Y. K. Ng, "Neuroprotection associated with running: is it a result of increased endogenous neurotrophic factors?" Neuroscience, vol. 118, no. 2, pp. 335-345, 2003.

[116] G. S. Griesbach, D. A. Hovda, R. Molteni, A. Wu, and F. Gomez-Pinilla, "Voluntary exercise following traumatic brain injury: brain-derived neurotrophic factor upregulation and recovery of function," Neuroscience, vol. 125, no. 1, pp. 129-139, 2004

[117] L. Tong, H. Shen, V. M. Perreau, R. Balazs, and C. W. Cotman, "Effects of exercise on gene-expression profile in the rat hippocampus," Neurobiology of Disease, vol. 8, no. 6, pp. 1046-1056, 2001.

[118] S. Colcombe and A. F. Kramer, "Fitness effects on the cognitive function of older adults: a meta-analytic study," Psychological Science, vol. 14, no. 2, pp. 125-130, 2003.

[119] M. Angevaren, G. Aufdemkampe, H. J. J. Verhaar, A. Aleman, and L. Vanhees, "Physical activity and enhanced fitness to improve cognitive function in older people without known 
cognitive impairment," Cochrane Database of Systematic Reviews, no. 2, Article ID CD005381, 2008.

[120] J. Gunstad, K. L. MacGregor, R. H. Paul et al., "Cardiac rehabilitation improves cognitive performance in older adults with cardiovascular disease," Journal of Cardiopulmonary Rehabilitation, vol. 25, no. 3, pp. 173-176, 2005.

[121] B. M. Quaney, L. A. Boyd, J. M. McDowd et al., "Aerobic exercise improves cognition and motor function poststroke," Neurorehabilitation and Neural Repair, vol. 23, no. 9, pp. 879885, 2009. 


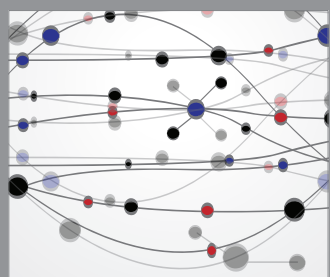

The Scientific World Journal
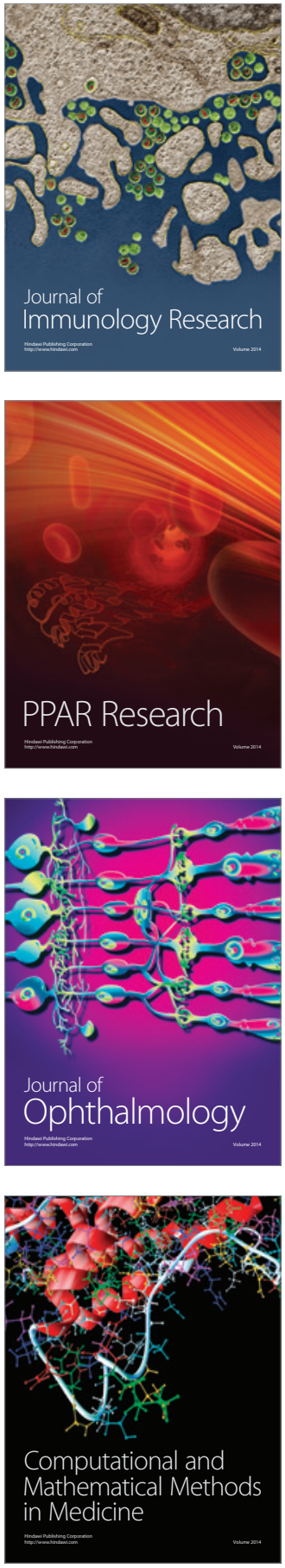

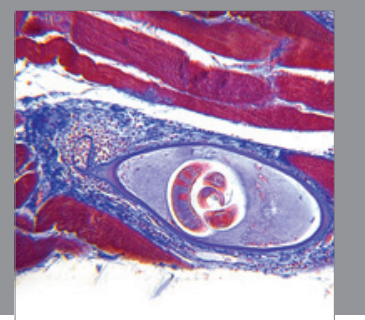

Gastroenterology

Research and Practice
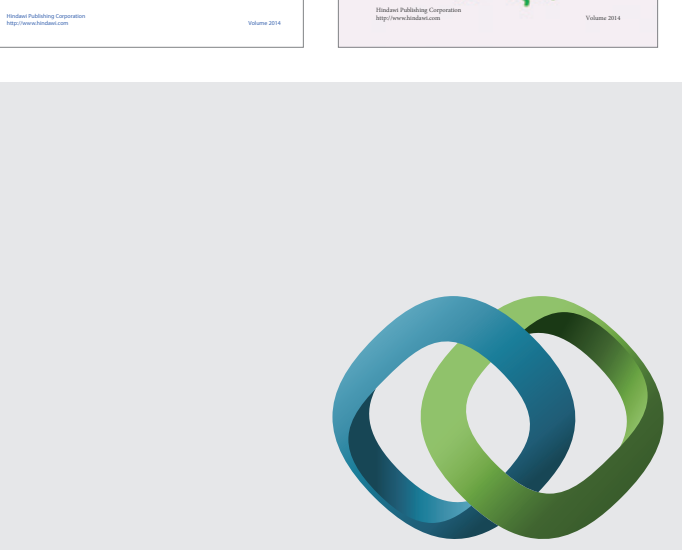

\section{Hindawi}

Submit your manuscripts at

http://www.hindawi.com
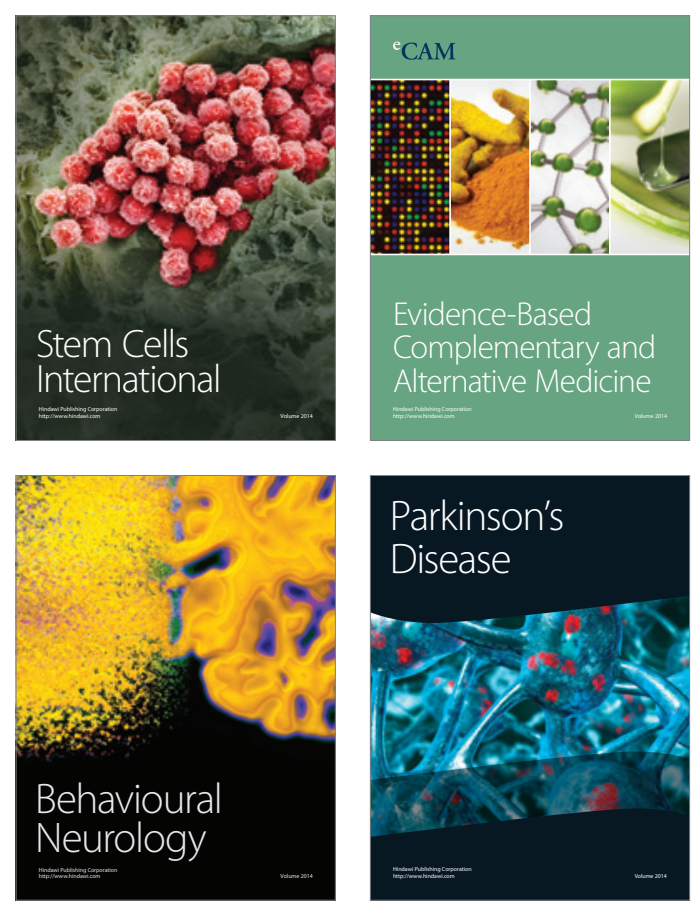

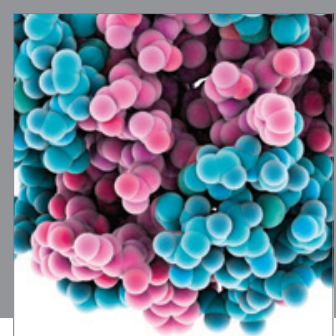

Journal of
Diabetes Research

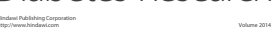

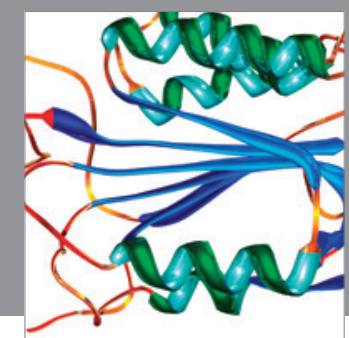

Disease Markers
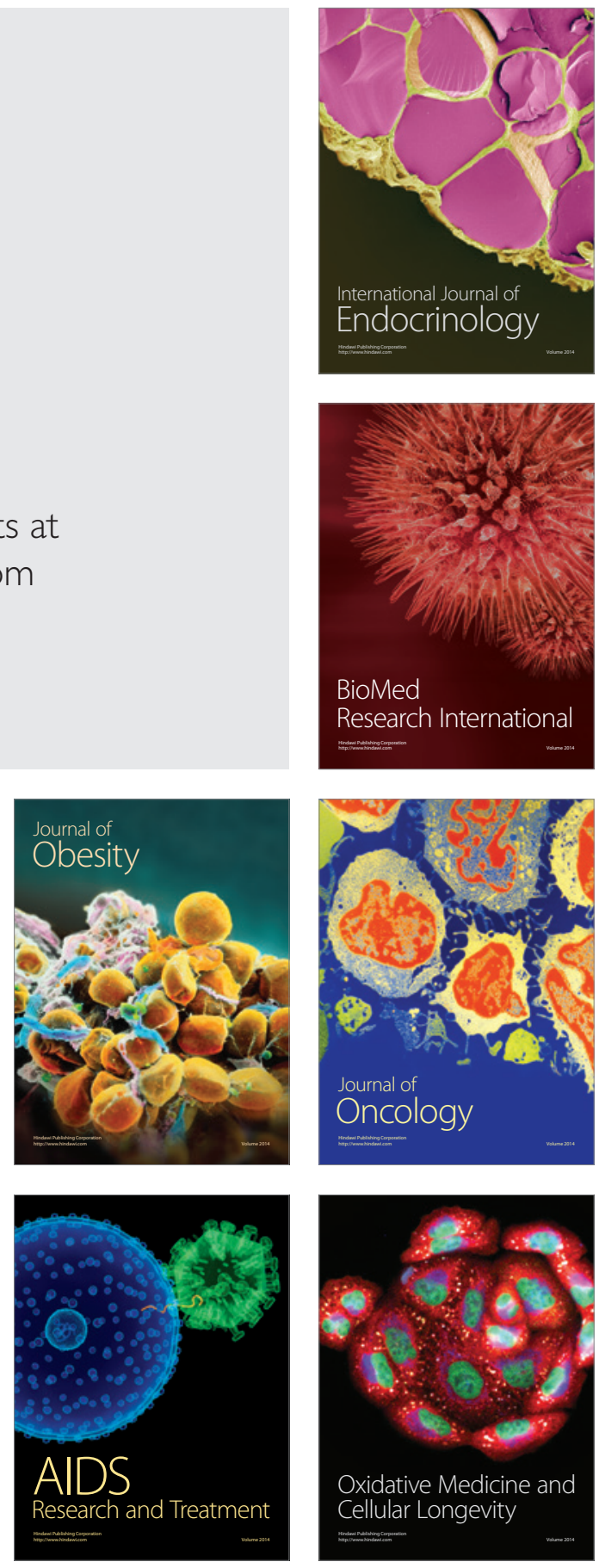